\title{
Analisis Perubahan Kebijakan Luar Negeri Iran Menyepakati JCPOA pada Masa Pemerintahan Hassan Rouhani
}

\author{
Abdullah \\ Program Studi Hubungan Internasional Universitas Brawijaya \\ e-mail: a.assegaf@ub.ac.id
}

\section{Abstract}

At the end of 2013, Iran agreed to the P5+1 joint agreement, which became the forerunner of the Joint Comprehensive Plan of Action (JCPOA), signed on July 14, 2015. Iran signed the deal to make the international community recognize its nuclear program and lift sanctions against the country. Previously, from 2003 to 2012, Iran had always refused to negotiate with the West. This phenomenon raises the research question discussed in this article: what causes Iran's policy change regarding its nuclear project. The research was conducted by literature study, utilizing official documents and mass media reports. In this study, the author uses the theory of foreign policymaking as described by Snyder et al. The result obtained is that the changing of Iranian foreign policy was influenced by the internal factors, especially the political and economic dynamics under President Hasan Rouhani. External factors also became the impetus for Iran to change its policies, including the policy changes made by Obama in the second term of his leadership and the endorsement of the deal from the European Union, Russia, and China.

Keywords: external factor, foreign policy, internal factor, Iran, JCPOA

\section{Abstrak}

Pada akhir 2013, Iran menyepakati kesepakatan bersama P5+1 yang menjadi cikal bakal Joint Comprehensive Plan of Action (JCPOA) yang ditandatangani pada $14 \mathrm{Juli}$ 2015. Keputusan ini diambil Iran dengan tujuan agar dunia internasional memberikan pengakuan terhadap program nuklirnya dan mencabut sanksi terhadap negara tersebut. Sebelumnya, sejak tahun 2003 hingga 2012, Iran selalu menolak berunding dengan Barat. Fenomena ini memunculkan pertanyaan penelitian yang dibahas dalam artikel ini, yaitu apa penyebab perubahan kebijakan Iran terkait proyek nuklirnya. Penelitian dilakukan melalui studi pustaka dengan 
memanfaatkan dokumen-dokumen resmi dan pemberitaan media massa. Dalam penelitian ini, penulis menggunakan teori pengambilan kebijakan luar negeri yang dijabarkan Snyder, et. al. Hasil yang didapatkan adalah perubahan ini dipengaruhi oleh faktor internal, terutama dinamika politik dan ekonomi di bawah kepemimpinan Presiden Hasan Rouhani. Faktor eksternal juga menjadi pendorong bagi Iran untuk mengubah kebijakannya, antara lain perubahan kebijakan yang dilakukan Obama pada periode kedua kepemimpinannya yang mendapat dukungan Uni Eropa, Rusia, dan China.

Kata kunci: faktor eksternal, faktor internal, Iran, JCPOA, kebijakan luar negeri

\section{Pendahuluan}

Komunitas internasional sejak tahun 1968 telah menyepakati perjanjian Nuclear Non-Proliferation Treaty (NPT) yang mengatur kepemilikan senjata nuklir dan mencegah penyebaran senjata nuklir, namun juga memberikan kesempatan bagi semua pihak untuk memanfaatkan energi nuklir untuk tujuan damai. Negara-negara yang telah menandatangani NPT terikat secara hukum untuk mematuhi isi perjanjian ini dan program nuklir mereka diawasi oleh PBB melalui The International Atomic Energy Agency (IAEA).

Namun demikian, beberapa kasus pengembangan nuklir oleh sejumlah negara tetap menjadi isu internasional yang selalu diperdebatkan dalam berbagai forum internasional. Salah satu isu nuklir yang menjadi pusat perhatian dunia internasional selama beberapa tahun terakhir adalah isu nuklir Iran. Hal ini terjadi karena hubungan Iran dengan negara-negara Barat, terutama Amerika Serikat (AS), kurang harmonis dan AS selalu menuding Iran tengah membuat senjata nuklir yang mengancam keamanan dunia. Tudingan ini ditepis pihak Iran dengan menegaskan bahwa teknologi nuklir yang dikembangkan hanya dimanfaatkan untuk tujuan damai.

Di bawah pemerintahan Ahmadinejad komitmen Iran untuk tetap melanjutkan program nuklir semakin kuat. Dengan dukungan parlemen dan Pemimpin Spritual Ali Khamenei, Iran tetap mempertahankan proyek nuklirnya walaupun terus menerima beberapa kali ultimatum serta sanksi ekonomi dan teknologi. Atas desakan AS, Dewan Keamanan Perserikatan Bangsa-Bangsa (DK-PBB) telah lima kali mengeluarkan resolusi yang sebagian besar memberlakukan sanksi terhadap Teheran. ${ }^{1}$ Kelima resolusi

\footnotetext{
${ }^{1}$ Sejak tahun 2006 hingga tahun 2009 PBB telah mengeluarkan lima resolusi dalam menyikapi permasalahan nuklir Iran, yaitu resolusi nomor 1696 dan nomor 1737 tahun 2006, resolusi nomor 1747 tahun 2007, serta resolusi nomor1803 dan nomor 1835 tahun 2008.
} 
tersebut dikeluarkan karena penolakan Iran terhadap negosiasi yang ditawarkan negara P5+1 (AS, China, Rusia, Inggris, Perancis, dan Jerman).

Kebijakan luar negeri Iran yang terus mempertahankan proyek nuklirnya direspons AS dengan memberikan sanksi yang lebih keras berupa embargo ekonomi kepada Iran dan mengeluarkan Iran dari pasar uang internasional. Sikap AS ini dengan cepat diikuti oleh sekutunya Uni Eropa dengan mengeluarkan sanksi baru terhadap Iran. Pada 23 Januari 2012, Dewan Uni Eropa bergabung dengan AS dalam babak baru pengenaan sanksi melalui pelarangan impor minyak dari Iran dan membekukan asetaset Bank Sentral Iran. Akibat dari sanksi internasional yang terus meningkat, perekonomian Iran pun mulai memburuk (Huang, 2016).

Situasi yang konfrontatif ini akhirnya mulai berubah setelah terpilihnya Hassan Rouhani, seorang politikus dari kalangan reformis, sebagai Presiden pada tahun 2013. Terpilihnya Rouhani menandakan adanya perubahan dalam dinamika politik Iran yang menginginkan perubahan atas kebijakan luar negeri pemerintahan sebelumnya yang telah banyak mendatangkan sanksi-sanksi berat terhadap Iran. Sebagai upaya untuk untuk membebaskan Iran dari isolasi ekonomi dunia internasional dan menyelesaikan isu nuklir Iran, Rouhani bersedia menyepakati perjanjian internasional Joint Comprehensive Plan of Action (JCPOA). Perjanjian tersebut dijalin antara Iran dengan kelima anggota tetap DK-PBB ditambah Jerman (P5+1) di Vienna pada tanggal 14 Juli 2015 (US Department of State, 2015).

Artikel ini membahas perubahan kebijakan luar negeri Iran sejak berkuasanya Hassan Rouhani, dari yang semula bersifat konfrontatif menjadi moderat dan kompromistis dengan menyepakati JCPOA.

\section{Faktor Internal dan Faktor Eksternal dalam Kebijakan Luar Negeri}

Dalam menganalisis permasalahan tersebut, penulis menggunakan teori pengambilan kebijakan luar negeri yang dijabarkan Richard C. Snyder, H.W. Bruck, \& Burton Sapin (1962). Dalam tulisannya Snyder melihat bahwa kebijakan suatu negara bukanlah hal yang tiba-tiba terjadi melainkan dibentuk oleh faktor internal dan faktor eksternal yang mempengaruhi lahirnya kebijakan tersebut. Indikator faktor internal bisa dilihat dari beberapa variabel yakni kondisi politik domestik, dan keadaan ekonomi. Sedangkan faktor eksternal akan menjelaskan dimensi lingkungan internasional yang mempengaruhi Iran dalam menyepakati JCPOA. Faktor eksternal mencerminkan suatu lingkungan internasional yang mendorong diputuskannya kebijakan suatu negara. Lebih lanjut, faktor eksternal merupakan tuntutan masyarakat atau suatu organisasi atau sekelompok tertentu mengenai isu yang dibahas dalam pembuatan kebijakan. Tuntutan tersebut menjadi salah satu pertimbangan dalam pembentukan kebijakan luar negeri. 
Dengan demikian, langkah Iran mengubah kebijakannya dengan menyepakati JCPOA telah mendapat dukungan lingkungan internasional yang menjadi stimulus terjadinya kesepakatan tersebut. Lingkungan internasional yang dimaksud adalah negara semacam AS, Rusia, China, dan Uni Eropa menjadi pihak yang signifikan sebagai aktor yang berperan dalam terjadinya perubahan kebijakan yang diambil Iran. Kebijakan yang diambil Iran merupakan persetujuan kolektif dengan negara P5+1 dalam kerangkan perjanjian internasional yang bernama JCPOA. Sehingga analisis terhadap motivasi yang dimiliki negara-negara yang bersepakat dengan Iran menjadi penting untuk ditelaah lebih lanjut.

Penulis menggunakan metode penelitian kualitatif dengan cara berpikir deduktif. Dengan metode ini, data-data diperoleh dari fakta-fakta di lapangan yang bersifat dinamis dan keakuratannya tidak bisa diukur secara langsung. Namun demikian penulis sangat menekankan aspek kualitas dan relevansi data sebagai satu unsur yang sangat penting dalam mengamati fenomena yang ada. Cara berpikir deduktif dipakai karena penjelasan muncul dari kerangka pemikiran. Kerangka pemikiran yang masih bersifat umum dijabarkan dalam hal-hal yang bersifat lebih khusus. Adapun data yang diperoleh penulis berasal dari sumber sekunder berupa buku, laporan penelitian, jurnal, surat kabar, sumber internet, dan dokumen tertulis lainnya yang relevan. Tipe penelitian ini adalah eksplanatif karena bertujuan untuk memberikan penjelasan penyebab Presiden Hassan Rouhani mengubah kebijakan Iran dengan menyepakati JCPOA. Fokus penelitian adalah kebijakan luar negeri Iran terkait nuklir mulai tahun 2013 hingga tahun 2015. Tahun 2013 adalah tahun dimana perubahan kebijakan nuklir Iran pada masa pemerintahan Hassan Rouhani dimulai. Sedangkan pada tahun 2015 merupakan tahun tercapainya kesepakatan JCPOA dengan negara P5+1 yang penulis anggap sebagai klimaks dari kebijakan perubahan nuklir Iran.

\section{Profil Joint Comprehensive Plan of Action (JCPOA)}

Joint Comprehensive Plan of Action (JCPOA) merupakan suatu perjanjian internasional tentang pengembangan program nuklir Iran yang berhasil disepakati oleh Iran dan P5+1 pada tanggal 14 Juli 2015 di Vienna. JCPOA berisi tentang prosedur pengembangan program nuklir Iran yang akan digunakan untuk tujuan damai dan penghapusan sanksi-sanksi nuklir yang telah dibebankan oleh dunia internasional kepada Iran, seperti sanksi perdagangan, finansial, teknologi, dan energi. JCPOA juga bertujuan untuk menjaga perdamaian dan kesetabilan keamanan regional dan internasional, yang menjamin implementasi pengembangan program nuklir Iran akan dilakukan dengan tujuan damai dan berada dibawah pengawasan IAEA. 
JCPOA merupakan bagian dari tahap finalisasi perjanjian sementara Joint Plan of Action (JPOA) yang disepakati oleh Iran dan P5+1 pada tanggal 24 November 2013. Terdapat beberapa poin penting yang telah disepakati oleh Iran dan $\mathrm{P} 5+1$ dalam JPOA, seperti pembatasan fasilitas pengembangan program nuklir di Natanz, Fordow, dan Arak; pelaksanaan program nuklir Iran yang harus sesuai dengan rezim nuklir internasional NPT; penghapusan sanksi-sanksi nuklir Iran, baik sanksi multilateral maupun nasional (US Department of State, 2015). Selama tahap implementasi JPOA, Iran dan $\mathrm{P} 5+1$ telah melakukan negosiasi tentang prosedur pengembangan program nuklir Iran hingga menghasilkan dua kesepakatan penting, yaitu: framework Joint Comprehensive Plan of Action yang disepakati pada tanggal 2 April 2015 dan perjanjian internasional JCPOA pada tanggal 14 Juli 2015 (US Department of State, 2015).

Berdasarkan perjanjian JCPOA, ada sejumlah kegiatan pengembangan program nuklir Iran yang disepakati oleh Iran dan P5+1, yaitu: 1) kegiatan Research \& Development tentang pengembangan uranium di Natanz yang akan dibatasi hingga 5060 IR-1 sentrifugal dalam periode 10 tahun, dengan spesifikasi beberapa jenis uranium yang dikembangkan, seperti: IR-4, IR-5, IR-6, dan IR-8; 2) fasilitas pengembangan program nuklir Iran akan diubah menjadi pusat nuklir, fisika, dan teknologi; 3) pengembangan uranium di Natanz akan diturunkan hingga 3,7\% dalam periode 15 tahun; 4) produksi uranium Iran harus memenuhi standar internasional, dimana kapasitas persediaan uranium Iran harus tidak boleh lebih dari $300 \mathrm{~kg}$ dengan pengembangan uranium hexafluoride (UF6) sebesar 3,7\%.; dan 5) Iran sepakat untuk membangun kembali dan mendesain ulang reaktor riset heavy water di Arak dengan penggunaan reaktor dibawah 3,7\% dalam periode 15 tahun. Reaktor tersebut akan digunakan untuk tujuan damai dan memproduksi radioisotop yang akan dimanfaatkan dalam bidang kesehatan dan industri (US Department of State, 2015).

Berdasarkan annex II JCPOA, rencana penghapusan sanksi-sanksi nuklir Iran meliputi dua hal, yaitu pertama, penghapusan beberapa sanksi nuklir Iran yang disebutkan dalam Resolusi Dewan Keamanan PBB, meliputi: 1696 (2006), 1737 (2006), 1747 (2007), 1803 (2008), 1835 (2008), 1929 (2010) dan 2224 (2015); kedua, penghapusan semua sanksi dari Uni Eropa dan AS yang telah disebutkan dalam annex II, dimana pencabutan sanksi akan dilaksanakan setelah pelaksanaan tahap implementation day dan IAEA telah mengklarifikasi bahwa Iran telah melaksanakan program nuklir yang digunakan untuk tujuan damai sesuai dengan perjanjian JCPOA (US Department of State, 2015).

Berdasarkan perjanjian JCPOA, pelaksanaan pengembangan program nuklir Iran juga akan dilaksanakan secara transparan, dimana pengembangan program nuklir Iran akan didampingi dan diawasi oleh IAEA. Selain itu, tahap-tahap pelaksanaan 
pengembangan program nuklir Iran dilakukan berdasarkan annex $\mathrm{V}$ JCPOA dan akan dimasukkan ke dalam Iran's Safeguard Agreement dalam pasal 17 (b) (US Department of State, 2015). Adapun tahap-tahap pelaksanaan program nuklir Iran dalam annex V adalah sebagai berikut: pertama, finalisation day, yaitu periode disepakatinya perjanjian internasional Joint Comprehensive Plan of Action oleh Iran dan P5+1 pada tanggal 14 Juli 2015. Resolusi Dewan Keamanan PBB juga akan mengadopsi annex V nomer 18 untuk tahap adopting day yang kemudian diikuti oleh Uni Eropa. Dalam tahap ini, Iran juga akan mempersiapkan segala perlengkapan yang dibutuhkan dalam tahap adopting day (US Department of State, 2015).

Kedua, adoption day, yaitu kesepakatan yang terdapat dalam JCPOA mulai diadopsi oleh kedua belah pihak, dimana Iran mulai menjalankan program nuklirnya sesuai dengan perjanjian JCPOA sedangkan negara-negara P5+1 mulai mempersiapkan percabutan sanksi nuklir Iran. Tahap ini dilaksanakan dalam periode 90 hari setelah perjanjian JCPOA diadopsi dalam resolusi Dewan Keamanan PBB. Ketiga, implementation day, merupakan periode pelaksanaan perjanjian JCPOA, dimana Iran akan melaksanakan pengembangan program nuklir sesuai dengan peraturan yang terdapat dalam annex I, sementara P5+1 dan DK-PBB akan mencabut sanksi-sanksi nuklir Iran sesuai dengan kesepakatan yang terdapat dalam annex II JCPOA.

Keempat, transition day, yaitu tahap implementasi JCPOA yang dilaksanakan dalam periode 8 tahun setelah tahap adoption day, dimana persyaratan yang belum dipenuhi oleh negara-negara yang terlibat dalam tahap adopting day akan diselesaikan dalam tahap ini. Kelima, UN Security Council resolution Termination Day, yaitu periode pemberhentian semua resolusi Dewan keamanan PBB dan Dewan Keamanan PBB dan dengan demikian isu nuklir Iran tidak lagi dipermasalahkan. Tahap ini dilaksanakan dalam periode 10 tahun setelah tahap adopting day (US Department of State, 2015).

\section{Faktor Internal: Dinamika Politik dan Ekonomi Iran}

Berubahnya tampuk kepemimpinan dari tradisional konservatif ke reformis dengan terpilihnya Hassan Rouhani merupakan salah satu faktor penting dalam tercapainya kesepakatan nuklir Iran. Dia dianggap sebagai pemain kunci yang mencoba mencairkan hubungan antara Iran dan P $5+1$ yang selama ini menjadi hambatan. Ini tidak bisa dilepaskan dari platform politik yang telah disiapkan Rouhani, antara lain moderatisme dan retorika yang tidak sekonfrontatif pendahulunya, Mahmoud Ahmadinejad. Dalam forum perundingan, Rouhani terlihat menggunakan narasi dukungan pada pilar-pilar demokrasi dan tidak mendiskreditkan Barat sebagai ancaman yang harus disingkirkan. Sebagaimana disimpulkan Haris (2014) dalam Kayam (2017), "Rouhani tidak menutupi niatnya untuk mencapai kesepakatan [dengan Barat], ia 
mengatakan kepada parlemen Iran di awal masa jabatannya bahwa prioritas utama pemerintahnya adalah 'meredakan ketegangan dengan dunia luar'." Maka cara yang paling logis bagi Iran, menurut Rouhani, ialah dengan menekankan pendekatan diplomasi dan komunikasi untuk menyelesaikan perselisihan antara Iran dan negaranegara Barat.

Pilihan Rouhani untuk mendekati Barat mendapatkan dukungan dari sebagian rakyat Iran karena bagi mereka krisis nuklir Iran dan embargo yang mengiringinya telah semakin menjenuhkan. Masyarakat cenderung menginginkan agar sanksi segera dicabut. Kecenderungan masyarakat ini terlihat dari kemenangan Rouhani sendiri pada pemilihan presiden tahun 2013 dan kemenangan faksi reformis dalam pemilu parlemen tahun 2016. Dalam pemilu 2016 itu, kubu reformis yang menyuarakan hubungan yang lebih terbuka dengan Barat memenangi 85 kursi. Sementara itu, kubu moderatkonservatif, yaitu kubu konsevatif yang pro-perjanjian nuklir dengan Barat memenangi 73 kursi. Dengan demikian, dua kubu yang sama-sama pro-perjanjian nuklir ini menduduki kursi mayoritas di parlemen Iran (Fisher, 2016)

\section{Grafik 1 Produksi Minyak Iran 2011-2015}

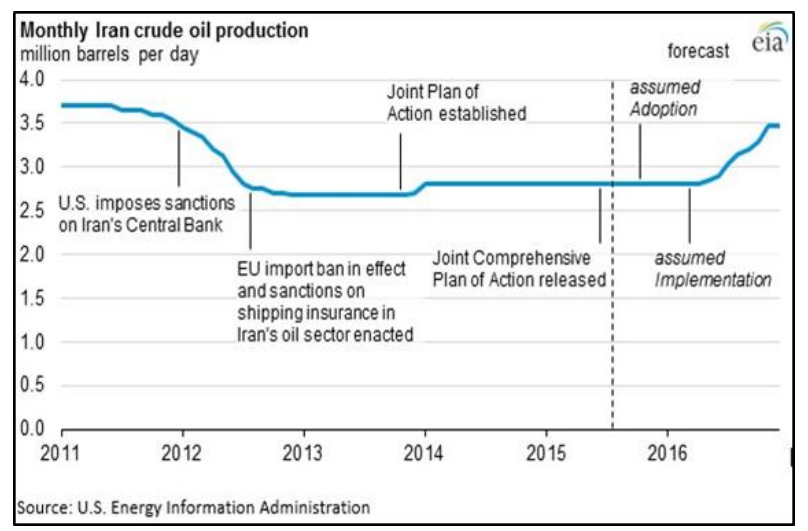

Sumber: Green (2015)

Kondisi ekonomi Iran sebelum tercapainya kesepakatan nuklir mengalami kendala yang cukup berat. Hal ini dibuktikan dengan pada awal Oktober 2012, nilai Riyal Iran turun sampai ke level 40\%, disusul dengan inflasi tahunan meroket $30.5 \%$ (Focus Economics, 2017). Menurut data tahun 2013, ekspor minyak mentah Iran menurun drastis dari 4 juta barel menjadi 1,25 juta barel per hari. Sektor industri Iran juga terdampak akibat sanksi. Sektor otomotif, misalnya, termasuk paling terpuruk. Produksinya turun dari 1,5 juta menjadi 1 juta hanya pada tahun 2012. Akibatnya produsen mobil internasional yang beroperasi di Iran terpaksa meninggalkan negara itu. Selain itu, bidang kesehatan juga terdampak akibat berkurangnya pasokan obat-obatan 
dari luar negeri akibat sanksi internasional yang mempersulit transfer dana yang dilakukan Bank Sentral Iran (Nikaeen, 2013).

Merosotnya ekonomi Iran juga terlihat pada Grafik 1. di atas, dijelaskan bahwa di tahun 2012, Amerika Serikat telah menjatuhkan sanksi terhadap Bank Sentral Iran yang mengakibatkan produksi minyak di Iran menurun dari angka kurang dari 3.5 juta barel. Kemudian di pertengahan tahun 2012-2013 Uni Eropa telah memberlakukan larangan impor minyak dan menerapkan sanksi terhadap pengiriman asuransi sektor minyak Iran yang mengakibatkan produksi minyak di Iran semakin turun jauh dari angka sebelumnya dibawah 3.0 juta barel.

Perekonomian Iran pada periode pertama pemerintahan Ahmadinejad menunjukkan perekonomian pertumbuhan positif, misalnya angka inflasi yang hanya mencapai $12 \%$, pertumbuhan ekonomi mencapai 7\%, kurs Dollar terhadap Rial Iran berada di kisaran 20.000 Rial per Dollar AS. Namun demikian, di periode kedua, seiring dengan berlanjutnya berbagai sanksi dan embargo ekonomi, kondisi perekonomian semakin melemah dan diikuti dengan revisi kebijakan ekonomi, dan dampak sosial, politik lainnya. Misalnya pada tahun 2012 pemerintah Iran mengurangi subsidi pangan dan bahan bakar juga dicabut sehingga menyebabkan kenaikan harga bahan-bahan pokok. Beberapa aksi demo juga terjadi sebagai bentuk ketidakpuasan masyarakat khususnya kaum bazaari (pedagang pasar) akibat kondisi perekonomian yang semakin memburuk. Misalnya, pada tanggal 3 Oktober 2012 aksi demo berujung kerusuhan muncul di Teheran dipicu oleh keruntuhan nilai Rial Iran (Zarback, 2013).

Terpilihnya Hassan Rouhani pada pemilu Juni 2013 dengan meraih 50,71\% menunjukkan bahwa sebagian masyarakat Iran menghendaki perubahan, terutama terkait dicabutnya berbagai embargo oleh Barat. Hal ini pula yang dijanjikan Rouhani pada masa kampanyenya. Antara lain, Rouhani menjanjikan bahwa kesepakatan nuklir dengan Barat akan membawa bantuan ekonomi dan membuka hubungan dengan dunia luar, yang akan meningkatkan "martabat dan kebanggaan Iran" (Fisher, 2016).

Janji Rouhani seputar nuklir sejalan dengan background-nya di bidang nuklir. Rouhani merupakan kepala negosiator nuklir Iran pada tahun 2003 hingga 2005, yang berusaha menjalin kesepakatan dengan Uni Eropa pada November 2013, yang berisi penangguhan sementara pemrosesan ulang uranium Iran dan janji untuk bekerja sama sepenuhnya dengan IAEA. Namun, terjadi perbedaan interpretasi atas berbagai klausul dalam kesepakatan ini sehingga kesepakatan tersebut gagal. Namun demikian, peran Rouhani dalam upaya ini menjadikannya sebagai tokoh dengan reputasi positif di Barat, sehingga ia dijuluki "syekh diplomat." Namun demikian, segera setelah Ahmadinejad 
terpilih sebagai presiden, Rouhani mengundurkan diri sebagai kepala negosiator karena tidak setuju dengan retorika Ahmadinejad yang konfrontatif (Sherrill, 2014).

\section{Faktor Eksternal: Dinamika Politik di Negara-Negara P5+1}

\section{A. Dinamika Politik di Amerika Serikat}

Terwujudnya JCPOA tidak terlepas dari dinamika politik di Amerika Serikat, terutama di masa pemerintahan Obama. Bila di pihak Iran, Rouhani memunculkan sikap yang lebih kooperatif, di pihak Amerika Serikat, Obama muncul dengan kebijakan yang lebih moderat dibandingkan presiden dari kalangan Republikan.

Hubungan bilateral AS dengan Iran sudah putus semenjak terjadi Revolusi Islam Iran pada tahun 1979. Hubungan diplomatik Iran dan AS di era monarkhi Iran, yang dipimpin Shah Reza Pahlevi sangat harmonis dan pada saat itu Iran merupakan sekutu utama AS di kawasan. Tergulingnya Pahlevi membuat kepentingan AS di Iran sangat terganggu dan AS melakukan berbagai upaya untuk melindungi kepentingannya. Mahasiswa-mahasiswa meresponnya dengan menduduki Kedutaan Besar AS di Teheran selama 444 hari sebagai bentuk protes atas intervensi AS. Akibat peristiwa ini, AS memutuskan hubungan diplomatik dengan Iran yang berlanjut hingga kini.

Di bawah pemerintahan Bush, AS menggunakan pendekatan yang koersif dengan mengecam dan memberikan sanksi terhadap Iran. Washington juga berulang kali mengancam akan menggunakan kekuatan militer terhadap Iran apabila Iran tidak mau bekerjasama terkait dengan program nuklirnya. Di sisi lain, pihak Iran menyatakan tidak akan mundur dari program pengembangan nuklirnya dengan mengatasanamakan hak nasional bangsa Iran yang sejalan dengan NPT yang telah ditandatanganinya.

Memasuki era pemerintahan Obama, pencapaian kesepakatan dengan Iran terkait program nuklirnya masih menjadi tantangan dalam kebijakan luar negeri AS. Sekilas, upaya yang ditempuh oleh Obama untuk membuat Iran menghentikan program nuklirnya tampak tidak jauh berbeda dengan yang dilakukan oleh Bush. Meskipun tidak bertumpu pada kekuatan militer, AS di bawah Obama memperketat banyak sanksi yang telah diberlakukan terhadap Iran sebelumnya dengan memperluas embargo yang telah diberlakukan pada tahun 2010. Bahkan, sebagai respons atas tidak tercapainya kesepakatan dengan pihak Iran dalam perundingan nuklir, AS dan negara-negara sekutunya di Eropa memberlakukan embargo minyak di tahun 2012, dalam arti Iran dihalangi untuk menjual minyaknya ke pasar internasional. Kebijakan AS tersebut terjadi, menurut hemat penulis, sebagai respons atas kebijakan Ahmadinejad yang konfrontatif terhadap AS. 
Di periode kedua (2012-2017), Obama mengubah kebijakannya dengan lebih lunak, hal ini tampak dari sikap Obama dalam beberapa forum menginginkan agar dunia internasional menginisiasi dan ikut ambil andil mendorong Iran untuk lebih kooperatif dalam menyelesaikan masalah nuklirnya. Periode kedua Obama berlangsung hampir bersamaan dengan terpilihnya Hassan Rouhani sebagai presiden Iran pada tahun 2013. Hal ini menjadi lembaran baru bagi hubungan diplomatik AS-Iran. Di bawah kepemimpinan Rouhani, Iran lebih mengedepankan perundingan sebagai jalan untuk mendapatkan kesepakatan. Kondisi ini sejalan dengan rencana Obama yang menginginkan mediasi sebagai upaya terbaik dalam menyikapi program nuklir Iran.

Perubahan kebijakan yang dilakukan Obama menunjukkan nilai-nilai dasar yang dianut oleh AS, yaitu adalah pragmatisme, suatu falsafah yang menekankan bahwa kebenaran akan teruji apabila mempunyai nilai manfaat. Pragmatisme sebagai the way of life bangsa AS mempengaruhi sikap politik luar negeri mereka melalui diplomasi politik yang pragmatis. Pragmatisme mengajarkan betapa pentingnya pengalaman sebagai bagian dari perkembangan dan kemajuan hidup manusia. Demikian pula pengalaman sangat berperan dalam politik luar negeri AS. Pelajaran yang diperoleh dari pengalaman diplomatik hampir selalu mempengaruhi proses keputusan diplomasi AS (Minderop, 2006: 115).

Dalam isu nuklir Iran, sikap pragmatisme ini ditunjukkan dengan jelas oleh Obama. Dengan kata lain, mencairnya hubungan diplomatik AS dan Iran pada periode kedua pemerintahan Obama merupakan bentuk pragmatisme politik luar negeri AS. Pragmatisme yang mengajarkan pengalaman sebagai legitimasi dan asas manfaat sebagai teori pembuktian kebenaran membawa arah politik luar negeri AS yang berbeda-beda setiap generasi. Misalnya pada masa kepresidenan Bush, AS cenderung bersikap koersif dengan ancaman perang terhadap Iran.

Adapun pragmatisme perubahan politik luar negeri AS pada masa Obama disebabkan oleh dua motif yaitu; pertama, pengalaman sebagai legitimasi. AS memiliki pengalaman pahit terkait perang di Afganistan dan Irak yang begitu banyak menyedot perhatian luar negeri AS dengan manfaat yang tidak terlalu banyak namun memberikan kerugian yang sangat besar. Perang di Irak menghabiskan setidaknya 3 (tiga) triliun US dollar dan mengeruk cadangan devisa dan memupuk utang luar negeri sehingga tatkala terjadi kolapsnya industri finansial AS pada tahun 2008, menyeret negeri Paman Sam ini ke dalam resesi dan krisis berkepanjangan. Pengalaman ini menjadi pelajaran pahit bagi AS untuk tidak lagi menggunakan senjata dalam menghadapi Iran dan mulai menggunakan diplomasi lunak. Hal ini kian terbukti tatkala John Kerry mengadakan perbincangan rahasia dengan Menteri Luar Negeri Iran di Oman pada pertengahan Agustus 2013. 
Kedua, asas manfaat. Bisa jadi dengan memanfaatkan Iran, AS akan memperoleh manfaat ganda. AS menyadari, semenjak Shah Pahlevi, sejatinya Iran memiliki kekuatan politis yang sangat kuat di Timur Tengah dibanding Arab Saudi. AS mulai sadar bawa penyelesaian isu-isu besar di Timur Tengah tidak bisa dilakukan menggunakan satu arah saja, tetapi harus melalui pendekatan dua arah. Arah pertama adalah Israel dan Arab Saudi, arah kedua adalah Iran. Dengan kata lain AS mulai merangkul dua pihak yang saling berseteru di Timur Tengah ini. Dengan melakukan dua pendekatan ini, AS berharap manfaat lain muncul dimulai dengan tercapainya JCPOA, perundingan Suriah, dan berbagai konflik sektarian di beberapa negara seperti Irak, Lebanon, dan Bahrain akan segera berakhir (Rizkiyanto, 2015).

\section{B. Dinamika Politik dan Ekonomi di Uni Eropa}

Uni Eropa hingga 10 tahun lalu merupakan salah satu audien utama politik luar negeri Iran dan menjadi mitra terpenting perdagangannya. Iran mengekspor minyak ke negara Yunani sebesar 14\%, Spanyol 14,6\%, dan Italia sebesar 13,1\% dari total konsumsi minyaknya. Akan tetapi kondisi tersebut telah berubah. Dalam beberapa tahun terakhir, hubungan bilateral Iran dan Uni Eropa tidak mengalami perkembangan berarti, dan bahkan hubungan kedua pihak mencapai titik terendahnya dalam tiga dekade terakhir menyangkut friksi soal program nuklir damai Iran (Pars Today, 2016).

Dalam menghadapi isu nuklir Iran, kebijakan masing-masing anggota Uni Eropa berbeda-beda. Inggris dan Perancis bersikap tegas dan vokal, sementara Jerman dan Italia cenderung lebih moderat dikarenakan keduanya merupakan mitra dagang terbesar Iran di Uni Eropa. Menteri luar negeri Jerman pernah mengatakan bahwa Iran merupakan pasar terpenting bagi Jerman di Timur Tengah (Hardianti, 2015:5). Sedangkan Uni Eropa harus bertindak sebagai sebuah institusi internasional dan bertindak bersama. Sementara itu proses pengambilan keputusan di Uni Eropa seringkali rumit dan kompleks.

Di sisi lain Uni Eropa juga mendapat tekanan-tekanan dari Kongres AS agar bersikap lebih keras dalam menghadapi isu nuklir Iran. Sehingga pada tahun 2006-2010 UE-3 dan AS telah berhasil mendorong DK-PBB untuk mengeluarkan resolusi terkait pengenaan sanksi ke Iran melalui resolusi No. 1737, 1747, 1803, 1835 dan 1929. Resolusi tersebut secara umum memberlakukan sanksi ekonomi, embargo, dan perdagangan serta larangan atas transaksi komoditas yang berhubungan dengan teknologi nuklir.

Pada dasarnya Uni Eropa cenderung lebih suka melakukan hubungan dengan Iran dalam format dialog. Kebijakan Uni Eropa terhadap Iran sangat berbeda dari kebijakan AS yang cenderung mengisolasi Iran. Uni Eropa tidak ingin Iran bernasib sama dengan Irak yang diserang AS pada tahun 2003. Hal ini dikarenakan kepentingan 
ekonomi dan strategis Uni Eropa di wilayah tersebut. Namun di sisi lain, Uni Eropa adalah sekutu AS dan mempunyai hubungan kerjasama Transatlantik (Hardianti, 2015: 7).

Pentingnya Iran sebagai pemain strategis di Timur Tengah, Iran sebagai penyedia sumber energi bagi Eropa dan masalah keamanan global, merupakan faktor krusial dalam menyikapi krisis nuklir Iran. Uni Eropa tidak hanya bergantung pada minyak dan gas Iran, namun juga mempunyai kepentingan korporasi yang besar di Iran dimana Iran merupakan mitra dagang dan pasar bagi Uni Eropa. Ditambah dengan adanya kerusuhan sipil di negara tetangga Irak dan Afghanistan, Uni Eropa menyadari pentingnya membawa Iran kembali ke panggung diplomatik dan politik internasional (Hardianti, 2015: 109-110). Dengan kata lain diakhirinya upaya isolasi internasional terhadap Iran menjadi fokus kebijakan Uni Eropa terhadap Iran.

Kembalinya Iran dalam perundingan nuklir menjadi momentum yang ditunggu oleh negara-negara Eropa. Momentum tersebut muncul kembali pasca kesepakatan Jenewa pada November 2013 sebagai tindak lanjut percakapan telepon antara Presiden Obama dan Presiden Rouhani. Pasca kesepakatan Jenewa berbagai delegasi tingkat tinggi Eropa telah berkunjung ke Teheran. Kunjungan Presiden Austria, Wakil Kanselir Jerman, Perdana Menteri Yunani, Ketua Parlemen Eropa, Presiden Swiss, Perdana Menteri Hongaria, Ketua Kebijakan Politik Luar Negeri Uni Eropa dan masih banyak lagi para menteri luar negeri dan ekonomi Eropa, semuanya mensinyalir tekad besar Uni Eropa memperluas hubungan bilateralnya dengan Iran (IRIB, 2016).

Kunjungan diplomatik Eropa mempunyai tujuan untuk mewujudkan kerjasama politik, perdagangan, perbankan, ilmiah, budaya dan juga penandatangan puluhan kesepakatan dan kontrak di semua lini. Tujuan tersebut telah mencerminkan pentingnya Iran di mata Uni Eropa. Kecenderungan besar Uni Eropa untuk meningkatkan hubungan dengan Iran dan perluasan interaksi diplomatik kedua negara telah membuktikan bahwa keberanian Uni Eropa untuk independen dan tidak terpengaruh kebijakan AS dalam berinteraksi dengan Iran (IRIB, 2016).

Semua kondisi yang telah disebutkan di atas menjadi pendorong bagi terciptanya situasi yang kondusif bagi tercapainya kesepakatan JCPOA pada 14 Juli 2015.

\section{Dinamika Politik dan Ekonomi China}

China merupakan negara anggota Dewan Keamanan PBB yang memiliki posisi yang cenderung bertentangan dengan AS. Oleh karena itulah, meskipun Dewan Keamanan PBB memberikan sanksi ekonomi kepada Iran, China tetap menjalin kerjasama ekonomi dengan Iran. Hal ini disebabkan karena power yang dimiliki China sehingga berani berbeda sikap dari AS dan orientasi China yang mengedepankan 
kepentingan nasionalnya di bidang ekonomi. Bagi China, Iran merupakan partner penting yang menyediakan gas alam untuk menjalankan roda perekonomian China. Bahkan, China berupaya membuat terowongan agar gas Iran bisa langsung mencapai negeri Tirai Bambu itu. Kerjasama China-Iran juga terwujud dalam bentuk penanaman modal. Ini dibuktikan dengan beberapa infrastruktur di Iran yang dibangun oleh pihak China, baik dari pihak pemerintah maupun pihak swasta. Eratnya hubungan Iran dan China juga dibuktikan dengan masuknya Iran dalam SCO (Sanghai Cooperatian Organization) pada tahun 2005. Dengan berbagai kerjasama diatas maka hubungan ekonomi China-Iran terus meningkat secara signifikan dari sebesar 400 juta dolar AS di tahun 1994 menjadi 29 milyar dolar AS pada tahun 2008.

Berikut ini rincian kontrak kerjasama kedua negara dalam bidang migas.

Tabel 1. Kontrak Investasi Perusahaan Minyak China di Iran tahun 2002-2010

\begin{tabular}{|c|c|c|c|}
\hline Tanggal & Projek & Perusahaan & Nilai \\
\hline Mei 2002 & Masjid-e-Soleyman (minyak) & $\begin{array}{l}\text { Sheer Energy (Kanada), } \\
\text { China National } \\
\text { Petroleum Company }\end{array}$ & $\$ 80$ Juta \\
\hline Januari 2004 & Azadegan (minyak) & $\begin{array}{l}\text { Inpex (Jepang), CNPC } \\
\text { menyetujui untuk } \\
\text { pengembangan } \\
\text { Azadegan Utara pada } \\
\text { Januari } 2009 \\
\end{array}$ & $\begin{array}{l}\text { \$200 Juta (Inpex) } \\
\$ 1.76 \text { Miliar (CNPC) }\end{array}$ \\
\hline Oktober 2004 & Yadaravan (minyak) & $\begin{array}{l}\text { Sinopec (China), } \\
\text { kesepakatan selesai } 9 \\
\text { Desember } 2007\end{array}$ & $\$ 2$ Miliar \\
\hline Juni 2006 & Garmsar bloc (minyak) & $\begin{array}{l}\text { Sinopec (Cina), } \\
\text { kesepakatan selesai } \\
\text { Desember } 2009\end{array}$ & \$20 Juta \\
\hline Juli 2006 & Ekspansi Kilang Arak & $\begin{array}{l}\text { Sinopec, JGC (Jepang). } \\
\text { Pekerjaan telah diambil } \\
\text { alih dengan industry } \\
\text { Hyundai (Korea } \\
\text { Selatan) }\end{array}$ & $\begin{array}{l}\text { \$959 Juta } \\
\text { (Perpanjangan } \\
\text { pekerjaan awal projek } \\
\text { Hyundai tidak } \\
\text { diketahui) } \\
\end{array}$ \\
\hline Desember 2006 & $\begin{array}{l}\text { Ladang gas Pars Utara (gas } \\
\text { lepas pantai, sudah } \\
\text { termasuk pembelian gas) }\end{array}$ & $\begin{array}{l}\text { China National } \\
\text { Offshore Oil Co. }\end{array}$ & \$16 Miliar \\
\hline Januari 2009 & Azadegan Utara & CNPC & \$1.75 Miliar \\
\hline Februari 2010 & Pars Selatan: Fase 11 & $\begin{array}{l}\text { CNPC (Pengeboran } \\
\text { akan yang sudah harus } \\
\text { mulai oada Maret } \\
\text { 2010, masih delay) }\end{array}$ & $\$ 4.7$ Miliar \\
\hline
\end{tabular}

Sumber: Katzman (2021) 
China adalah negara yang mendapatkan keuntungan dari embargo yang diberlakukan Barat. Pemberlakukan sanksi Barat terhadap Iran telah menimbulkan kekosongan investasi di Iran, dalam arti, negara-negara Barat yang selama ini telah menanamkan investasinya di sektor energi di Iran terpaksa menghentikan investasi mereka. Kekosongan investasi itu dimanfaatkan oleh China.

Sebagaimana terlihat pada Tabel 1. di atas, pada bulan Mei 2002, perusahaan Sheer Enegry di Kanada dan Perusahaan Petrolium Cina telah melakukan proyek minyak di kawasan Masjid-e-Soleyman dengan nilai sebesar 80 Juta USD. Pada Januari 2004, perusahaan Inpex asal Jepang bersamaan dengan CNPC telah melakukan persetujuan pengembangan proyek minyak di Azedagan Utara yang kemudian telah disetujui pada Januari 2009 dengan nilai sebesar 200 Juta USD (Inpex) dan 1.76 Miliar USD (CNPC). Kemudian kontrak kerja kembali terjadi di bulan Oktober 2004, di mana perusahaan China, Sinopec menggarap proyek minyak Yadaravan senilai 2 Miliar USD. Data lainnya mengenai kerja sama Iran-China dapat dilihat pada Tabel 2 di bawah ini.

Data-data ini memperlihatkan bahwa bersamaan penerapan sanksi baru pada 2009, China justru melakukan transaksi perdagangan dan investasi dengan Iran. Bahkan investasi tahun 2009 tercatat sebagai investasi terbesar Cina dibandingkan tahun-tahun sebelumnya, yakni mencapai 63 milyar Dolar AS di bidang energi (Whelman, 2010). Pemerintah China tidak menghiraukan desakan dari Barat untuk tidak melakukan kerjasama bisnis dan perdagangan minyak dengan Iran. China menganggap kerjasamanya dengan Iran bukanlah kerjasama yang terkait dengan sanksi dan merugikan negara lain maupun komunitas internasional. Sebagaimana yang telah disampaikan juru bicara Menteri Luar Negeri China, Jiang Yu, "China and Iran's normal commercial exchanges did not breach any UN resolutions, and will not harm the interest of any other country or the international community" (Aiyang, 2010).

Dalam kalkulasi rasional, China tidak memiliki kepentingan strategis dalam pelaksanaan sanksi terhadap Iran. Justru China akan mengalami kesulitan mencari alternatif kebutuhan energi dari negara lain jika Iran mengalihkan penjualan minyaknya ke negara lain. Terlebih lagi, kedua negara telah menyepakati kontrak pasokan gas dari Iran selama 25 tahun sejak tahun 2004. China juga memperhitungkan besarnya investasi yang ditanam di Iran dan aset-asetnya yang begitu besar. Pada tahun 2009 saja, nilai investasi China telah mencapai 120 milyar Dollar AS (Freeman, 2010). Dengan demikian, tekanan Barat terhadap China untuk menghentikan kerjasamanya dengan Iran tidaklah berarti apa-apa dibanding ancaman atas kerugian yang akan didapatkan jika Iran mengalihkan penjualan minyak dan gasnya. 
Tabel 2. Investasi Kerjasama Minyak China-Iran Pada Tahun 2008-2009

\begin{tabular}{|c|c|c|c|c|}
\hline Date & Company & Country & Project Detail & Notes \\
\hline $\begin{array}{l}\text { Aug } \\
2009\end{array}$ & CNPC & Iran & $\begin{array}{l}\text { MOU untuk kontrak } \\
\text { pembelian kembali untuk } \\
\text { dikembangkan Azadegan } \\
\text { Lapangan } \\
\text { Selatan. CNPC } 70 \% \text {, } \\
\text { Inpex } 10 \% \text {, NIOC } 20 \%)\end{array}$ & $\begin{array}{l}\text { CNPC berinvestasi USD } \\
2,25 \text { miliar dan Inpex } \\
\text { USD } 0,25 \text { miliar untuk } \\
\text { pengembangan tahap } \\
\text { pertama. }\end{array}$ \\
\hline $\begin{array}{l}\text { Jun } \\
2009\end{array}$ & CNPC & Iran & $\begin{array}{l}\text { Kesepakatan awal untuk } \\
\text { dikembangkan } \\
\text { Fase } 11 \text { bidang South Pars. } \\
\text { (CNPC } \\
40 \% \text {, NIOC } 50 \% \text {, Petronas } \\
10 \%)\end{array}$ & $\begin{array}{l}\text { Mitra bertujuan untuk } \\
\text { memproduksi } 1.765 \\
\text { bscf / d gas alam dan } \\
\text { produk lainnya. CNPC } \\
\text { menginvestasikan USD } \\
4,7 \text { miliar. }\end{array}$ \\
\hline $\begin{array}{l}\text { Jan } \\
2009\end{array}$ & CNPC & Iran & $\begin{array}{lr}\text { Kontrak } & \text { pengikatan } \\
\text { pembelian kembali untuk } \\
\text { eksplorasi } & \text { dan } \\
\text { pengembangan lapangan } \\
\text { Azadegan Utara selama } 25 \\
\text { tahun. }\end{array}$ & $\begin{array}{l}\text { CNPC diharapkan } \\
\text { mampu menghasilkan } \\
75 \mathrm{~kb} / \mathrm{d} \text { pada fase } \\
\text { pertama dan } 150 \mathrm{~kb} / \mathrm{d} \\
\text { pada fase kedua. In } \\
\text { akan menginvestasikan } \\
\text { USD } 1,76 \text { miliar pada } \\
\text { tahap pertama dan } \\
\text { total investasi } \\
\text { meningkat menjadi } \\
\text { USD 3,5 hingga } 4 \text { miliar } \\
\text { pada tahap kedua. }\end{array}$ \\
\hline 2008 & Sinopec & Iran & 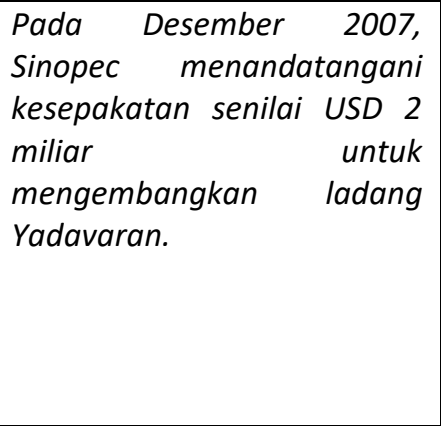 & $\begin{array}{l}\text { Di bawah fase I, } \\
\text { diharapkan untuk } \\
\text { menghasilkan } \\
85 \mathrm{~kb} / \mathrm{d} \text { dalam empat } \\
\text { tahun, meningkat } 100 \\
\mathrm{~kb} / \text { d dalam tiga tahun } \\
\text { di bawah fase II untuk } \\
\text { mencapai } 185 \mathrm{~kb} / \mathrm{d} \text {. } \\
\text { Pekerjaan dimulai pada } \\
\text { Sep 2008. }\end{array}$ \\
\hline
\end{tabular}

Sumber: www.iea.org

Meskipun Dewan Keamanan PBB menyepakati sanksi ekonomi terhadap program nuklir Iran, namun sebenarnya China menolak pemberlakuan sanksi tersebut. Di atas meja perundingan dalam membicarakan sanksi, China senantiasa menyatakan bahwa sanksi bukanlah solusi dalam masalah nuklir Iran dan setiap negara berhak menentukan mitra kerjasama dan membeli barang-barang kebutuhannya sendiri tanpa harus ada yang membatasi. Sejak dikeluarkannya resolusi tahun 2006 terhadap Iran, China tidak pernah melaksanakan sanksi terhadap Iran sebagaimana yang dikehendaki 
dalam ketetapan resolusi, baik di bidang perdagangan, keuangan, maupun bantuan terhadap program nuklir Iran.

China menjelaskan kepada Iran bahwasanya pihaknya telah berusaha bersungguh-sungguh dan terlibat secara aktif dalam konsultasi setiap rancangan resolusi dan bekerja keras bahwa setiap resolusi harus sesuai dengan prinsip-prinsip politik luar negeri China terhadap Iran dan menegaskan komitmennya untuk menyelesaikan secara damai masalah nuklir Iran. Posisi China yang berpihak kepada Iran ini memberikan dorongan kepada Iran untuk tetap bersedia melanjutkan perundingan nuklirnya sampai akhirnya JCPOA berhasil ditandatangani pada tahun 2015.

\section{Dinamika Politik dan Ekonomi Rusia}

Posisi Rusia, sebagaimana China, juga menunjukkan pembelaan kepada Iran. Sejak awal, Rusia menekankan agar permasalahan nuklir Iran diselesaikan dalam perundingan diplomatik. Tidak sama dengan AS dan sekutunya, Rusia memandang bahwa Iran sebagai penandatangan NPT berhak mengembangkan nuklir damai. Hal ini sejalan dengan kepentingan nasional Rusia yang juga diuntungkan dalam pengembangan nuklir Iran karena Rusia adalah salah satu mitra penting dalam pengembangan nuklir Iran.

Rusia merupakan negara yang mempunyai hubungan diplomatik yang dekat dengan Iran dibandingkan dengan negara lainnya di Benua Eropa. Hubungan dekat tersebut dilihat dari adanya bantuan Rusia untuk mengaktifkan kembali program nuklir Iran pasca Revolusi Islam Iran. Kerjasama antar dua negara tersebut dimulai pada tahun 1992 dalam pembangunan reaktor nuklir Busher melalui perusahaan Rusia, Atomstroiexport. Pada tahun 1995, kedua negara yang diwakili oleh Viktor Mikhailov (Russia Ministry of Atomic Energy) dan AEOI yang diwakili oleh Reza Ainrollahi di bawah naungan IAEA menyepakati kerjasama pembangunan nuklir. Iran mengajukan proposal agar pembangunan reaktor pertamanya selesai dalam waktu 4 tahun. Perjanjian pembangunan reaktor tersebut bernilai $\$ 800$ milyar yang secara keseluruhan diselesaikan dalam waktu 10 tahun (Kerlie, 2014).

Selanjutnya pada Juli 2002, Rusia mendeklarasikan bahwa negara itu akan menyelesaikan pembangunan reaktor nuklir di Bushehr yang menghabiskan dana sebesar 840 juta dolar (Miglietta, 2006: 10). Rusia juga sepakat untuk mengirimkan mesin V-320 915 MWe WER-1000 pressurized water reactor ke dalam reaktor di Bushehr (Akbar, 2015: 6). Selain itu Rusia juga berencana akan membangun lima reaktor dalam beberapa dekade ke depan (satu di Bushehr, empat lagi di Ahvaz, 40 mil dari Teheran) (Akbar, 2015: 6). 
Selain kerjasama dalam pengembangan program nuklir, kedua negara juga menjalin kerjasama di bidang militer. Iran merupakan salah satu pangsa pasar terbesar Rusia dalam perdagangan senjata di Timur Tengah (Formentini \& Milani, 2012). Nilai perdagangan senjata kedua negara tersebut konsisten dari tahun 1992 hingga 2003 mencapai 3.988 juta Dollar AS. Kerjasama terus berlanjut hingga tahun 2006 ketika Rusia mengekspor pesawat tempur multi role Su-30 MK 2 Flanker dan 18 helikopter, serta sistem pertahanan udara Tor-1 kepada Iran (Arms Control Association, 2014). Yang terakhir, pada tahun 2007 Rusia-Iran mempunyai kontrak pengadaan pertahanan udara S-300 dengan nilai transaksi mencapai 800 juta dollar (Akbar, 2015: 6).

Alasan Rusia dalam mendukung nuklir Iran adalah Rusia menganggap ancaman AS dan Uni Eropa sebagai prioritas kebijakan luar negeri. Hal yang sama juga dirasakan Iran, yaitu bahwa AS dan UE selalu memberikan tekanan dan embargo kepada Iran. Dukungan Rusia terhadap program nuklir bisa diartikan sebagai pesan Moscow kepada Teheran untuk menjalin aliansi militer dalam menghadapi ancaman tersebut. Selain itu Rusia juga perlu mengerem hegemoni AS di Timur Tengah, karena hampir mayoritas negara Teluk merupakan aliansi AS. Maka menjalin aliansi dengan Iran merupakan bagian kebijakan Rusia dalam mengamankan kepentingan nasionalnya.

Rusia juga ingin menunjukkan kembali kepada dunia bahwa Rusia masih merupakan salah satu negara terkuat di dunia, menjadi salah satu negara adikuasa seperti Uni Soviet dahulu. Hal tersebut merupakan cita-cita yang juga ingin diwujudkan oleh Rusia itu sendiri. Namun demikian, cita-cita tersebut tidak akan dapat terjadi jika AS masih menjadi negara terkuat di dunia. Oleh karena itu, Rusia perlu mengimbangi kekuatan AS, pengimbangan kekuatan Amerika itu diwujudkan Rusia dengan melakukan kerjasama dengan negara-negara musuh AS, salah satunya Iran (Gidadhubli, 2006).

Selain itu, aliansi militer Rusia-Iran memiliki tujuan untuk menahan agresi militer, melakukan operasi antiteroris, memerangi kejahatan transnasional. Aliansi tersebut secara permanen berbasis di Rusia dan di bawah satu komando dengan negara-negara anggota CSTO (Collective Security Treaty Organization) dengan mengkontribusikan unit militer khusus. Pemerintah Rusia di Kyrgyzstan menempatkan satuan militer hingga seukuran satu batalyon dan Rusia mendirikan pusat pelatihan untuk personil militer kedua negara. Perjanjian tersebut berlaku selama 49 tahun dan dapat secara otomatis diperpanjang sampai periode 25 tahun lagi (Barbanov, 2009).

Rusia secara konsisten memberikan respons penolakan terhadap pemberian sanksi yang lebih berat terhadap Iran. Meskipun pada akhirnya selama kurun waktu 2006-2009 Dewan Keamanan PBB telah mengeluarkan 5 resolusi terkait isu nuklir Iran, namun peran Rusia sangat signifikan di dalam meringankan resolusi yang memuat sanksi 
terhadap Iran tersebut. Bahkan, Rusia juga menawarkan diri sebagai negara yang nanti akan membantu Iran dalam menjalankan nuklirnya dengan syarat kapasitas nuklirnya hanya 3,5\% sebagaimana yang tercantum dalam JCPOA. Selama kurun waktu sanksi, kerjasama Iran dengan Rusia mengalami hambatan akibat tekanan AS. Hal ini nampak dengan ditangguhkannya pengiriman sistem pertahanan udara S-300 hingga tahun 2014 dan juga tertundanya penyelesaian reaktor Busher yang baru selesai pada 2011.

Berdasarkan berbagai kondisi yang telah disebutkan, Rusia terus mendorong Iran agar kembali ke meja perundingan dan hal ini menjadi salah satu faktor pendorong utama tercapainya kesepakatan nuklir antara Iran dengan negara P5+1 melalui JCPOA 2015.

\section{Simpulan}

Ditandatanganinya JCPOA pada tahun 2015 oleh Iran dan P5+1 dapat dianalisis dengan konsep kebijakan luar negeri yang dikemukakan Sneyder, et.al., yaitu bahwa terdapat situasi internal dan eksternal yang mempengaruhi atas perubahan kebijakan yang diambil suatu negara. Dalam tercapainya kesepakatan JCPOA 2015, ada perubahan situasi internal yang menjadi pendorong utama, yaitu perubahan kondisi politik di dalam negeri Iran di bawah kepemimpinan Rouhani. Rouhani merupakan politisi dari kalangan reformis yang menginginkan agar Iran lebih kooperatif dan terbuka dengan Barat, dengan harapan embargo ekonomi terhadap Iran bisa dicabut. Kebijakan yang diambil Rouhani dengan menandatangani JCPOA seiring dengan dinamika politik internal di tengah masyarakat Iran yang semakin tertekan oleh kemerosotan ekonomi dan mengharapkan Rouhani bisa memenuhi janji kampanyenya untuk memperbaiki ekonomi melalui upaya pencabutan embargo dari Barat.

Sementara itu, di level eksternal, negara-negara P5+1 juga memiliki dinamikanya masing-masing yang memberikan dorongan kepada Iran sehingga akhirnya menyepakati JCPOA. Pemerintah AS di bawah Barack Obama menunjukkan sikap yang lebih moderat dan pragmatis, sehingga bersedia memberikan berbagai janji konsesi dalam JCPOA. Sementara itu, negara-negara Uni Eropa memiliki kepentingan ekonomi yang besar di Iran dan kepentingan ini terganggu oleh kebijakan embargo dari AS. Oleh karena itu, Uni Eropa sangat mendorong terwujudnya JCPOA. Terwujudnya kesepakatan tersebut juga tidak bisa dipisahkan dari peran China dan Rusia. Kedua negara tersebut mengambil posisi sebagai pembela Iran sehingga mendorong Iran untuk menyepakati JCPOA. Posisi China dan Rusia ini dimotivasi oleh kepentingan ekonomi karena dengan dicabutnya sanksi, kedua negara ini akan lebih leluasa dalam menjalin kerjasama dengan Iran dalam berbagai aspek. 


\section{Daftar Pustaka}

Aiyang. (2010). China's FM says trade tie with Iran Normal. China Daily. [online]. Dalam: http://www.chinadaily.com.cn/china/2010-08/04/content_11096648.htm [Diakses 21 Februari 2017]

Akbar, Z. E. (2015). Kepentingan Rusia Dibalik Dukungannya Terhadap Program Nuklir Iran. Jurnal IImu Hubungan Internasional FISIP Universitas Jember XII (1), 1-11.

Arms Control Association. (2014). Background and Status of Iran's Nuclear Program. [Online]. Dalam: https://www.armscontrol.org/reports/Solving-the-IranianNuclear-Puzzel/2014/06/Section_one [Diakses 22 Februari 2017].

Barbanov, M. (2009). Russian Tank Production Sets A New Record. Moscow Defense Brief. [Online] Dalam: http://mdb.cast.ru/mdb/22009/item4/article1/ [Diakses pada 9 Maret 2017]

Fisher, M. (2016). How the nuclear deal boosted Iran's moderates - and showed Iranian elections can matter. Vox, [Online]. Dalam: https://www.vox.com/2016/3/2/11147102/iran-election-moderates-nuclear-deal. [Diakses pada 20 Mei 2021].

Focus Economics. (2017). Iran Economy Outlook. [Online]. Dalam: http://www.focuseconomics.com/countries/iran [Diakses 20 Februari 2020].

Formentini \& Milani, T. (2012). The Legal Status of Caspian Sea: History of the Treaties between the Riparian States. Working Paper European Center for Energy Security Analysis, 3(4).

Freeman, C. (2010). The China Factor in Iran's Nuclear Strategy. [Online]. CSIS, Dalam: https://www.csis.org/analysis/china-factor-irans-nuclear-strategy [diakses pada 01 Maret 2017].

Gidadhubli, R.G. (2006). Oil and Politics in Russia, Tightening Grip on Pipelines. Economic and Political Weekly, Oxford University Press. 41(31).

Green, M. (2015). Oil Exports, Iran and U.S. Global Competitiveness. Dalam: https://www.api.org/news-policy-and-issues/blog/2015/08/14/oil-exports-iranand-us-global-competiti [Diakses pada 21 Februari 2021]. 
Hardianti, E. (2015). Kebijakan Uni Eropa dalam Menghentikan Proliferasi Nuklir Iran tahun 2009-2013. Tidak Diterbitkan, Skripsi, Universitas Islam Negeri Syarif Hidayatullah Jakarta.

Huang, X. (2016). The Iranian Nuclear Issue and Regional Security: Dilemmas, Responses, and The Futures. [Online] UN. Dalam: https://hr.un.org/sites/hr.un.org/files/The\%20Iranian\%20Nuclear\%20Issue\%20an d\%20Regional\% 20Security.pdf, [Diakses pada 05 Januari 2017].

IRIB. (2016). Interaksi Uni Eropa Terhadap Iran. [Online] Indonesian IRIB. Dalam: http://indonesian.irib.ir/ranah/telisik/item/108272-interaksi-uni-eropa-terhadapiran [Diakses pada 20 Januari 2017].

Katzman, K. (2021), Iran Sanctions, CRS Report RS20871. Dalam: https://crsreports.congress.gov/product/details?prodcode=RS20871

Kayam, O. (2017). A rhetorical change that changed reality Rouhani vs. Ahmadinejad at the UN. Language and Dialogue, 7 (2), 163-188.

Kerlie, K. (2014) Iran Will Not Reverse Engineer Russian S-300 Missile Defense System. Sputniknews, [Online]. Dalam: http://sputniknews.com/middleeast/20150511/1022002757.html\#ixzz3Zu4nbcPU http://www.jmss.org/jmss/index.php/jmss/article/download/159/181] [Diakses pada 22 Februari 2017]

Miglietta, J. P. (2006). Iran, the Nuclear Option, and the NPT Treaty: The Implications and Ramifications on Iranian Foreign Policy. Paper presented at the Annual Meeting of the International Studies Association, [Online] Dalam: http://citation.allacademic.com//meta/p_mla_apa_research_citation/0/9/8/4/6/p ages98465/p98465-10.php [Diakses pada 20 Februari 2017]

Minderop, A. (2006). Pragmatisme Sikap Hidup dan prinsip Politik Luar Negeri Amerika, Jakarta: Yayasan Obor Indonesia.

Nikaeen, S. (2013). Tercekiknya Perekonomian Iran. DW, [Online]. Dalam: http://www.dw.com/id/tercekiknya-perekonomian-iran/a-16876297 [Diakses pada 20 Januari 2017].

Pars Today. (2016). Iran dan Uni Eropa Pada Periode Pasca JCPOA 1. [Online]. Dalam: http://parstoday.com/id/radio/world-i26764 iran_dan_uni_eropa_pada_periode_pasca_jcpoa_1 [Diakses pada 20 Februari 2017]. 
Rizkiyanto, S. (2015). Kesepakatan Geneva Sebagai Bentuk Pragmatisme Politik Luar Negeri AS Di Timur Tengah. Jurnal Sosial dan Budaya Syar'i, 2(1).

Sherrill, C.W. (2014). Why Hassan Rouhani Won Iran's 2013 Presidential Election. Middleeast Policy, 21(2).

Snyder, R. C., Bruck, H.W., \& Sapin, B. (1962). Foreign Policy Decision-Making : An Approach to the Study of International Politics. New York: The Free Press.

US Department of State. (2015). Joint Comprehensive Plan of Action. [online] Dalam: https://2009-2017.state.gov/e/eb/tfs/spi/iran/jcpoa/index.htm [Diakses 21 Februari 2020].

Whelman, A. F. (2010). China-Iran Foreign Relations. [Online] Critical Threats. Dalam: https://www.criticalthreats.org/analysis/china-iran-foreign-relations [Diakses pada 01 Maret 2017].

Zarback, Y. (2013). Kemana Janji Muluk Ahmadinejad. DW, [Online]. Dalam: http://www.dw.com/id/kemana-janji-muluk-ahmadinejad/a-16844586] [Diakses pada 10 Januari 2017]. 